Были подобраны и проведены такие методики, как: Подростковый опросник (Г. Айзенка); Самоактуализационный тест (Э. Шостром); Методика определения профессиональной готовности (Л. Н. Кабордовой).

На основании результатов, полученных в ходе проведения подобранных методик, был проведён эмпирический анализ различий личностных особенностей у студентов социономических и технических направлений профессиональной подготовки. На основании этого были выявлены различия средних показателей индивидуальных особенностей. Анализ показал, что студенты социономических направлений профессиональной подготовки болле общительны, контактны, креативней. Студенты технических направлений профессиональной подготовки обладают более повышенной серьезностью и независимостью суждений.

Были выявлены значительные различия средних показателей личностных особенностей у студентов социономических и технических направлений профессиональной подготовки, в результате чего гипотеза была подтверждена.

$$
* * *
$$

1. Абульханова-Славская. К. А. Психология и сознание личности (проблемы методологии, теории и исследования реальной личности): избранные психололгические труды [Текст] / К. А. АбульхановаСлавская. - Москва. - МПСИ, 2000. - С. 72-73.

2. Андерсонс. Г. В. Концептуальное обоснование содержания педагогической поддержки старшеклассников в выборе будущей профессий[Текст] / Г. В. Андерсон. Воронеж: ВГПУ. - 2006. $35 \mathrm{c}$.

3. Бордаченко. С. И. Профессиональная подготовка студентов гуманитарного вуза в области математики дис. канд. пед. наук [Текст] / С. И. Бордаченко. - Сходня, 2003. - 60 с.

4. Егоров. И. В. Динамика взаимосвязи самооценки и социально-психологических качеств личности студентов педагогического вуза [Электронный ресурс] / И. В. Егоров. - Режим доступа: http://www.dslib.net/soc-psixologia/dinamika-vzaimosvjazi-samoocenki-i-socialno-psihologicheskihkachestv-lichnosti.html. Дата обращения: 20. 122017.

5. Куликов. Л. ВПсихология личности в трудах отечественных психологов[Текст] / Л. В. Куликов. Питер, 2005. -48 с.

\title{
Усманов Р.Ф. \\ Организационные аспекты разрешения конфликта интересов в органах внутренних дел Российской Федерации
}

Академия управления МВД России

(Россия, Москва)

doi 10.18411/spc-04-03-2018-30

idsp 000001:spc-04-03-2018-30

Разрешение конфликта интересов в органах внутренних дел Российской Федерации представляет собой нормативно закрепленную и организационно обеспеченную процедуру, позволяющую идентифицировать (выявлять) состояние конфликта интересов (мнимый или реальный конфликт); анализировать содержание конфликта интересов (источники или причины конфликта интересов индивидуальные, организационные; цели, ценности, мотивы носителей конфликта); осуществлять поиск, установление, реализацию организационных средств и методов его разрешения.Разрешение конфликта интересов должно основываться на единых методологических подходах, а также на использовании комбинированных средств и методов; ориентироваться на реализацию преимущественно не карательных, а предупредительных мер; способствовать достижению баланса публичных и частных интересов на правоохранительной службе, созданию благоприятных правовых и организационных условий невыгодности интересов и игнорирования интересов службы, как для служащего (коллектива), так и организации вступления в конфликт.

Основой разрешения организационного конфликта является отведение противоречивых функций по различным должностным лицам, отделам или ведомствам. Принцип недопустимости совмещения бюрократической и государственно- 
предпринимательской деятельности должен дополнить уже принятое требование недопустимости совмещения нормотворчества и другой правоприменительной деятельности, контрольно-надзорной деятельности.

Одним из наиболее нежелательных из организационных конфликтов является конфликт между требованиями инструкций и требованиями достижения плановых показателей. В этой ситуации правоохранительные органы сталкиваются с противоречивыми требованиями. С одной стороны, от них требуется соблюдать требования закона, а с другой стороны требуется достижение количественных показателей. Достижение же в результате применения закона какого-либо конкретного показателя возможно только при систематической тенденциозности в применении закона.

Еще один организационный конфликт может проистекать из того, что в разных органах существенно различается отслеживание выполняемых действий и конечных результатов деятельности. Неправильный выбор способа контроля создает стимулы для агентов сосредоточиться непосредственно на требованиях отчетности вместо надлежащей организации работы. Характерный пример: многочисленные побочные последствия (в связи с изменениями критериев и показателей ведомственной оценки) от применения последовательно меняющихся систем показателей оценки работы сотрудников в системе МВД России.

Кроме того, стоит указать на проблему появления «неправовых» или «незаконных поручений» к должностным лицам, также приводящих к конфликту интересов. Сегодня должностное лицо не защищено от неблагоприятных для него последствий в случае невыполнения такого поручения, что создает предпосылки для появления таких поручений и их последующего выполнения. Однако если брать в расчет интересы не отдельного лица, сделавшего незаконное поручение, а интересы государства в целом, то выполнение незаконного приказа также является коррупцией нарушением других поручений, даваемых государством агенту - должностному лицу.

Для наиболее качественного и благоприятного разрешения конфликта интересов в деятельности органов внутренних дел Российской Федерации необходимо обратить внимание на административный учет. В данное время он ведется преимущественно в бумажной форме, тогда как все большее количество действий (межведомственная переписка, ведение баз данных и так далее) ведется в электронной форме. При этом электронная информация в отличие от сохраненной на бумаге имеет справочный статус, она не обладает свойством официальной признанности. Эта ситуация искусственно порождает необходимость дублирования электронных технологий бумажными, что создает ненужные издержки. В этой связи необходимо определить требования, обеспечивающие полезность использования учета; возможность независимого аудита, судебной экспертизы, оперативно-розыскных действий и иных форм проверки содержания и функционирования системы учета; требования к защите систем электронного административного учета, к их прозрачности для граждан, доступности; основные принципы выделения бюджетных средств на приведение в соответствие с требованиями действующих систем учета.

Конфликты интересов порождаются целым комплексом обстоятельств организационного характера. Все это позволяет утверждать, что необходима комплексная система разрешения конфликта интересов, которая позволяла бы контролировать поведение не только публичных должностных лиц, но и организаций и отдельных людей, которые хотели бы повлиять на формирование государственных решений.

В этом смысле совершенствование организационных основ разрешения конфликта интересов сотрудников органов внутренних дел подразумевает, в первую очередь, создание эффективной системы, позволяющей своевременно диагностировать (выявлять) ситуации конфликта интересов в системе органов внутренних дел, 
устанавливать причины (условия) возникновения конфликта интересов, круг заинтересованных сторон конфликта, а также своевременно влиять на данные условия, то есть приводить личные интересы сотрудников органов внутренних дел и самой организации к единому результату на основе апробированных организационноправовых средств.

Система разрешения конфликта интересов, должна действовать на основе следующих принципов:

- обязательное раскрытие сведений о реальном или потенциальном конфликте интересов или даже видимости такого конфликта;

- индивидуальное рассмотрение, оценка серьезности рисков для органов внутренних дел каждого конфликта интересов и урегулирование каждого случая конфликта интересов;

- конфиденциальность процесса раскрытия сведений о конфликте интересов и процесса урегулирования (при желании сотрудников);

- соблюдение баланса интересов органов внутренних дел и сотрудника при урегулировании конфликта интересов;

- защита сотрудника от преследования в связи с конфликтом интересов, который был своевременно раскрыт самим сотрудником.

В целях совершенствования организационного обеспечения разрешения конфликта интересов в органах внутренних дел необходимо:

- осуществлять предупреждение конфликта интересов на основе следующих принципов: обязательное раскрытие сведений о реальном или потенциальном конфликте или даже его потенциальной возможности; индивидуальное рассмотрение, оценка серьезности рисков для органов внутренних дел каждого конфликта; конфиденциальность процесса раскрытия сведений о конфликте интересов и процесса урегулирования; соблюдение баланса интересов органов внутренних дел и сотрудника при урегулировании конфликта интересов; защита сотрудника от преследования в связи с конфликтом интересов, о котором был своевременно информирован сотрудником руководитель;

- использовать при разрешении конфликта интересов (потенциального или реального) различные варианты и формы его урегулирования: отстранение от отдельных работ; делегирование полномочий; отставка; отказ от личных интересов; отказ от подарков и иных выгод; повышение прозрачности и тщательный анализ принимаемых решений;

- создать в органах внутренних дел комиссии по соблюдению требований служебной дисциплины и урегулированию конфликта интересов вместо комиссий по служебной дисциплине и профессиональной этике;

- создать систему обучения поведению в ситуациях конфликта интересов сотрудников органов внутренних дел; сформировать перечень должностей в системе органов внутренних дел, в наибольшей степени подверженных риску коррупции; обеспечить доступ физических и юридических лиц к информации о деятельности органов внутренних дел; расширить обратную связи с получателями государственных услуг; внедрить современные информационно-коммуникационные технологии, обеспечивающие максимальную автоматизацию административноуправленческих процессов; развивать технические средства контроля за деятельностью сотрудников, замещающих должности, в наибольшей степени подверженных риску коррупции, а также применять технические средства контроля деятельности сотрудников в процессе исполнения служебных функций, связанных с непосредственным контактом с физическими и юридическими лицами.

$$
* * *
$$

1. Делягин М.Н. Государственное управление: проблемы и перспективы Проблемы теории и практики управления. 1999. №6. С. 26. 
2. Тонков Е.Е Управление конфликтами в органах внутренних дел: Учебное пособие. - Белгород: ОН и РИО, 2001.

3. Матвеев Д.Д. Организационные методы разрешения конфликта интересов в служебной деятельности сотрудников органов внутренних дел // Закон и право. 2008. №4.

4. Матвеев Д.Д. Урегулирование конфликтов интересов начальником городских и районных органов внутренних дел // Совершенствование управления в системе горрайорганов внутренних дел на современном этапе. Материалы межкафедральной научно-практической конференции в Академии управления МВД России. - М., 2006.

5. Авторский коллектив: В.К. Русаков, Л.М. Колодкин, Г.П. Лозовицкая, О.М. Боева, А.С. Горелов, А.Я. Балкаров, Р.А. Умеров, М.В. Дукманов, О.В. Сибилева Теоретические основы и практика работы кадровых подразделений органов внутренних дел Российской Федерации по вопросам прохождения службы. М.: Академия управления МВД России, 2017. - 88 с.

\section{Чикурова П.С., Березина А.В. \\ Ментальность и проживание в общежитии как один из факторов адаптации иногородних учащихся (на примере студентов УГЛТУг.Екатеринбург)}

Уральский государственный лесотехнический университет (Россия, Екатеринбург)

doi 10.18411/spc-04-03-2018-31

idsp 000001:spc-04-03-2018-31

Проблема качества образования, освоения студентами профессиональных знаний и навыков напрямую связана с условиями их проживания, реакцией на окружающую среду и ее восприятие. Актуализация данной проблематики раскрывается при обращении к теме адаптации иногородних студентов, не только к условиям мегаполиса, но и к совместной с другими студентами жизни в общежитии. Как быстро адаптируется первокурсник к жизни вне семьи, без постоянных контактов с родными и близкими? Являются ли условия проживания одним из самых важных факторов адаптации студентов в новом городе?

Существующая проблематика отмечается не только в вузах Екатеринбурга, а так же и в других регионах России [2].Нередко встречаемые проблемы привыкания иногородних молодых людейк новой для них жизни студентов вуза связываются с целым наборомсоциальных, экономических и бытовых проблем, а так же и ментальными проблемами жителей периферии.

Основной задачей, стоящих перед первокурсниками, стала социализация в незнакомых для них условиях мегаполиса и системы вузовского образования. Выбор направления адаптации распределялся следующим образом:

1. стараться соответствовать окружению, подстраиваться под окружающих, не конфликтовать;

2. привлечь внимание сокурсников к своей личности;

3. вести всегда и везде собственную линию, помнить о цели поступления.

На первый взгляд, студентыраспределяются только на три группы, согласно выбору направления адаптации к новым условиям, но в реальности картина представляется наиболее сложной и зависит от ментальности обучающегося, его самоидентификации и применимых ценностей к оценке реальности и его окружения.Так, привлечь внимание однокурсников к своей личности можно, как и участием в общеуниверситетских мероприятиях, так и участием в довольно затратных городских «тусовках», растратой денежных средств, так и просто явно маргинальным поведением.

Как показывают исследования только 5 - 7 \% из опрошенных идут этим путем, активно участвуя в мероприятиях вуза, всего от $1-1,5 \%$ выбирают маргинальные направления, и около 4\% (у кого достаточно обеспеченные родители) проводят время в городских тусовках, вынося все молодежные новости на суд студенческой 